Journal of English Language Teaching and Applied Linguistics

ISSN: 2707-756X

DOI: $10.32996 /$ jeltal

Journal Homepage: www.al-kindipublisher.com/index.php/jeltal

\title{
Communicative Language Teaching in Teaching ESL for University Students
}

\author{
Le Thi Ngoc Hien 8 (iD \\ Ho Chi Minh City University of Food Industry, Ho Chi Minh City, Vietnam \\ $\triangle$ Corresponding Author: Le Thi Ngoc Hien, E-mail: hienltn@hufi.edu.vn
}

ARTICLE INFORMATION

Received: May 17, 2021

Accepted: June 13, 2021

Volume: 3

Issue: 6

DOI: 10.32996/jeltal.2021.3.6.7

\section{KEYWORDS}

Communicative Language

Teaching; CLT; university students;

advantages and disadvantages;

CLT classroom activities

\section{ABSTRACT}

Although teaching and learning language is not a new topic for researchers, it always inspires educators and linguists. Among new teaching approaches, Communicative Language Teaching (CLT) is a teaching method that emphasizes communicative output. This approach has been widely known worldwide since it was first introduced in the 1970s because of the demand for communication skills of language learners. However, there are still many issues raised because teachers are not similar to this method. In terms of language competence, Chomsky (1957) mentions linguistic aspects like lexis, syntax, phonology and morphology as the central part of learning language, while Hymes (1971) concludes grammatic, semantic, sociolinguistic and pragmatic aspects. Hymes' (1971) theory and other authors' theories lead to a new breakthrough in developing communicative language teaching in teaching and learning a second language. Compared with the Grammar-Translation method, CLT provides learners with more opportunities to develop their communicative ability and increase the role of learners in teaching and learning second language classroom activities, which is hard to find in other old teaching methods. This paper focuses on the overview of CLT in teaching English as a second language. In particular, it summarises the advantages and disadvantages of CLT comparing with old teaching methods, current trends of CLT, obstacles in applying CLT in the university context. Since then, it helps teachers have a better understanding of CLT and the article also suggests implications of teaching English with CLT in the university context, including designing classroom activities and motivating students.

\section{Introduction}

English ranks the fourth among languages that have the most people officially speak and it is the most popular language for international communication. Therefore, teaching and learning English is always a concern by educators and researchers worldwide, especially teaching English for university students entering the workforce right after graduation. Some people may think that university students have to be good at English because they have spent seven to more than ten years learning it. However, in Vietnam and other Asian countries, the English level of university students are various because of their educational background and ability. Coming from different places, including city, countryside, rural area or even mountainous village, most of them find English one of the most challenging subjects although they want to be good at English to find a better job. In general, the outcomes of students in Vietnam are relatively low, which is also found in other countries like in the researches of Abahussain (2016), Al-Nasser (2015), Alsalmi (2014), Batawi (2007). There are other reasons to explain the poor performance of university students in second language learning like teacher's teaching ability and quality, lack of actual chance of communicating with native people in English, which is supported by the research of Souriyavongsa et al. (2013) in the National University of Laos. Therefore, to increase the quality of teaching and learning English in University, many changes in different aspects need to be considered. Teaching methods should be specially discussed because teachers normally take the role of instructor and directly influence the learning process in the classroom.

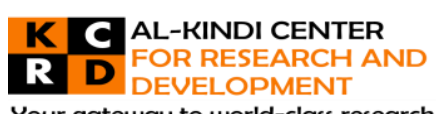

Your gateway to world-class research

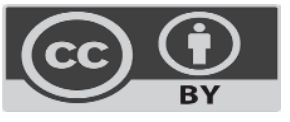

Published by Al-Kindi Center for Research and Development, United Kingdom. Copyright (c) the author(s). This open access article is distributed under a Creative Commons Attribution (CC-BY) 4.0 license 
English teachers need appropriate teaching methods to engage and motivate their students to improve their English ability. In terms of teaching method or approach, most English teachers are familiar with traditional teaching methods like the GrammarTranslation method, Direct method, Audiolingual, Community Language Learning, (De)Suggestopia Silent Way, or Total Physical Response. When traditional methods cannot satisfy the requirement of communication and interaction outcome (Dos Santos, 2019), modern teaching methods have been introduced to meet the need of recent learning and teaching English, including CLT, CBI (Content-Based Instruction), TBI (Task-Based Instruction). CLT, which requires spoken output, is proving its effectiveness when it meets learners' need for communicative competence. However, CLT has not very popular, especially in the university setting. By synthesising researches on CLT, the author wants to find the answer for three main questions.

Research questions

(1) What are the advantages of CLT in teaching and learning English as a second language?

(2) What are the disadvantages of CLT in teaching and learning English as a second language for university students?

(3) How to implement CLT effectively in teaching English as a second language in a university context?

\section{Literature Review}

CLT is the result of new demand in learning and teaching English. GMT had been dominant for a long time before the introduction of CLT. Many linguists claim that learning a language will be more effective when following natural methods. According to Richards and Rogers (2001), "believers in the Natural Method argued that a foreign language could be taught without translation or the use of the learner's native language if the meaning was conveyed directly through demonstration and action" (p.11). Learning a language is efficient when learners have more chance exposing to it, using it in real conversation. This process is not very different from learning their mother tongue. Therefore, the traditional methods that emphasise grammatical aspects and translation seem not to create a spontaneous environment for learners. CLT is an innovative language teaching which fosters and encourages learners to use their general knowledge and linguistic knowledge to solve real tasks like conversation, negotiation, persuade, making a decision, etc., which is supported by Riggenbach and Lazaraton (1991, p.125) when they mention CLT includes real-life activities between groups like negotiation or interaction. Through real and like-real practice, learners improve their English ability and are confident to use English to communicate with others.

Being introduced in 1970s, CLT has been considered and accepted in many countries (Phillipson, 1992; Pennycook, 1994; Kachru, 1992). Thompson (1996) claims that CLT is an alternative for the traditional teaching method GTM because it involves meaningful communication and requires communicative input and outcome. Learning with traditional methods, students may be good at grammar and vocabulary, but they are not confident to communicate with English speakers because they rarely have a chance to use their English knowledge in real conversation. English is a language, so if learners do not use it often, it is hard for them to memorise vocabulary and without real-life situation practises, their English cannot be a tool to communicate, but a subject at school. Widdowson (1990, p.159) describes CLT as an approach that allows learners to use language to do things, which means that tasks are seen as concepts, notions, and meaningful activities instead of a particular grammar point or separated language skills. Nunan (1991) includes five main features of CLT :

(1) Concentrating on learning to communicate in the target language.

(2) Using authentic texts in learning activities.

(3) Providing opportunities for learners to develop their language and learning process.

(4) Encouraging personal experience as an essential element for classroom activities.

(5) Attempting to connect classroom tasks with outside classroom activities.

Based on these features, Canale and Swain (1980, p. 4) introduce four communicative competence of CLT, including 'grammartical competence', 'sociolinguistic competence', 'discourse competence', and 'strategic competence' while Bachman (1990) divides it into 'organizational competence' and 'pragmatic competence'. CLT basically refers to the ability to use language 'receptively and productively' in real-life situations (Kiato and Kiato, 1996). CLT aims to exploit the ability to use much different knowledge, both general and linguistic, into meaningful tasks and activities which simulate real-life situations in order to develop learners' language aspects such as maintaining conversation despite the limitation in language knowledge, using language for different purposes and functions, using and understanding different types of texts, using appropriate language for a different setting like formal and informal situations (Richard, 2006). CLT method is also a good way to enrich learner's general knowledge like Doughty and Long (2003) states, "new knowledge is better integrated into long-term memory, and easier retrieved if tied to real-world events and activities" (p. 58). Authentic materials with tremendous knowledge of culture and different aspects from science to daily life of many different nations and even the universe provide learners updated information necessary for them to be successful in their work and life.

The role of teacher and student: in a traditional classroom, teachers are often in the role of controller, which is called teachercentred. In that learning environment, students are not as active and flexible as in CLT class, allowing students to be the center of 
teaching and learning process. It means students in CLT classes gain the initiative in classroom activities because the more they work hard in CLT classes, the more benefits they can gain, which is supported by Kennedy (2002) when he claims that CLT gives both teacher and students opportunity and flexibilities in a wide range to do activities. Teachers act the role of monitor and facilitator in classroom activities to engage students and support them when needed to motivate them to attend these activities actively. In addition, CLT focuses on the learner-centred role of students.

However, in practicality, the application of CLT in a particular context of universities in different countries faces various obstacles that need discussing to find solutions. As a normal phenomenon, a new method often faces difficulties and opposition. Firstly, teachers know the effectiveness of CLT, but they do not know how to apply it appropriately in their class (Dos Santos, 2016, 2017). Futhermore, Tomlimson (2001) also adds more evidence for the less common of CLT which is the domination of materials. Not all the contents in the textbook are designed for CLT because they provide a wide range of collaborative activities and some are not related to the context of the lesson. When teachers want to implement CLT in their classes, they need more extra content outside the textbook. Therefore, if the teacher sticks to activities in the textbook, it is very hard for them to turn a normal class into CLT class, whereas if they do not base on the content of the textbook, they may be criticized by the supervisors. Ozsevik (2010) points out that teachers who are 'abundened and unpaid' do not adapt CLT in teaching. The obstacle also comes from students, which is concluded through Walia's (2012) study. Students hesitate to CLT activities and the 'time constraints and the budget for CLT activities contribute to other disadvantages of implementing CLT method (Walia, 2012). In West's (2016) research, he points out that the instruction and the complication of vocabulary cause the problem for CLT activities. In terms of fluency and accuracy of language, some people argue that CLT focuses on fluency more than accuracy and as a result, even students who have good communicative abilities still make basic grammar errors. Nunan (1989) explains that is because learners pay more attention to meaning than linguistic structure.

During the real practice of $C L T$, specific setting faces their own difficulties. In Asian countries, most difficulties come from the contextual setting. In Vietnam, Pham (2007) and Iwashita and Ngoc (2012) mention conflicts affecting CLT implementation, including many students in a language class. In Thailand, Saengboon (2002) also mentions that the number of students in each class is too crowded and their level is different, so it is hard to do CLT activities. In South Korea, Jung and Norton (2002) suggest that most materials designed for large size class sot are not suitable for CLT activities. In Taiwan, Huang and Yang (2018) mention social cultures as the factors for the failure of CLT in this country. Even CLT in the United States of America still faces difficulties. International students coming from different cultures and language backgrounds are unwilling to engage in CLT activities because they have a strong belief in traditional methods and consider learning a language means learning vocabulary and grammar (Dos Santos, 2020; Ahn \& Kang, 2017; Lee \& Lee, 2019).

Another factor that affects the implementation CLT is the attitude of teachers and students. Teacher's belief is very important because it impacts on how they teach and what they teach. Borg (2017) states that their belief may be affected by many factors like their own personalities, experience as learners, and their practice assumption. Most teachers experienced GTM when they were trained at pedagogic schools and they have different characteristics and different time of practise, so that teachers still face some difficulties when applying CLT in their classes. The fact that not many teachers have received training about CLT (Abrejo et al., 2019). They may update new teaching methods by themselves instead of attending an official training course, which postponed them from apply CLT in their class. Most research on the implementation of CLT is based on teacher's point of view (Li, 1998), while few researchers see it through student's angle like Schulz (1996) or (Natividad \& Batang, 2018). Natividad and Batang (2018) claim that university students can learn best through group work and spoken language with actual experience. Therefore, students are in favour of CLT because it gives them a chance to work for meaningful communication, learning English by using it in context instead of momorising grammar points, and they can also develop their social skills when working in group with other people. Furthermore, learners' behavior contribute into the success or failure of CLT practise. Dos Santos (2020) states that East Asian students are not motivated and active like Western ones due to their cultural background, which may cause the limitation in some CLT activities like discussing or arguing to give final agreement.

The large size of the classroom also causes a disadvantage for CLT implementation. Normally in a university environment, the number of students is quite a crowd, about 50 students. Therefore, it is not easy for all of them to interact and communicate with each other in a limited time and the teachers cannot handle all conversation between students to give appropriate support or feedback for individual students (Weiner, 2012; Weiner \& Jerome, 2016).

In term of how much English used in CLT classes, there are controversial ideas. Brandl and Bauer (2002) claim that when teachers maximize the use of the second language, students in beginning classes prefer their teachers use more L1 (first language), especially in directions and confirming their understanding; whereas, when teachers use more L2 (second language), they would like their teachers to use more L1. 
In addition, during the implementation of CLT, there are several misunderstanding by educators. Thompson (1996) points out that CLT means not teaching grammar, pair work is the same as role-playing in CLT, and CLT brings a lot of pressure for teachers because they have to face unpredicted situations with high demand ability to debate. However, Thompson explains that CLT allows teaching language implicitly through other activities instead of ignoring linguistic aspects like grammar completely. When he mentions role play, Thompson distinguishes between pair work and role play for a simpler level repeating exactly the samples while pair work refers to the real interaction and real decision between attendants. However, for the last misconcept, the researcher does not have a clear answer because CLT is designed by native speakers and served their teaching. It is a reason for rejecting CLT, but it also a good way for teachers to improve their teaching and enhance their belief and practice. He also gives another reason for this misunderstanding: teachers who do not want to change their current teaching method.

CLT is one of the most effective methods in teaching and learning a second language because it provides opportunities for learners to practice and improve their communicative competence in pedagogic and real-life situations. Although it has not widely implemented in university schools yet, teachers and students have a positive attitude towards this method because of its benefits. The real practice of CLT in university school has shown advantages and disadvantages or difficulties both inside and outside the classroom. Therefore, teachers need to consider the real situation at their school to have effective implementation of CLT classes.

\section{Methodology}

Although CLT has introduced and been applied since 1970s, it has not widely been implemented in Vietnam and other Asian countries, especially at the tertiary level. Therefore, it is very difficult to conduct quantitative or qualitative research at a particular university. This article would like to analyse some important aspects related to the implication of CLT into university context by collecting information from more than fifty articles and research on CLT in teaching English as a second language or foreign language in Asian universities because the contexts in these research are rather similar to Vietnam so that the results of analysis and suggestions will be more practical and valuable for future implementing of CLT in teaching English for university students in Vietnam. Based on the literature review, the article aims to discuss three main questions mentioned in the introduction by analysing the advantages and disadvantages of CLT in teaching and learning English as a second language. Since then, the author makes suggestions about implementing CLT effectively in teaching and learning English at the tertiary level.

\section{Results}

The literature review looking at CLT from many different aspects provides evidence for the author to answer three main questions.

\subsection{Advantages of CLT in teaching and learning English as second language}

CLT has been mentioned since 1970s and developed through three main stages to show its innovation to meet each period's demand. For a long time, GTM has been widely implementing in teaching and learning English, but the weakness outweighed the strength, which leads to the introduction of CLT.

$\mathrm{CLT}$ is considered as the best solution in improving the communicative competence of learners. Based on principles of CLT, Nunan (1991) points out five main features of CLT. Canale and Swain (1980) and Bachman (1990) introduce the communicative competence of CLT. CLT focuses on communicative input and outcome when it requires authentic material, communication between learners, which uses both general knowledge and linguistic knowledge, linking inside the class and the world outside through life-like situations. Moreover, to effectively join CLT activities, learners should exploit and develop their sociolinguistic, discourse, strategic, and grammatical competence or organizational and pragmatic competence. As a result, learners acquire the target language effectively in both implicit and explicit ways. Another advantage of CLT is the active role of learners in classroom activities. In traditional classes, learners passively obtain knowledge which mainly comes from their teachers and given textbook. It means that good students (who follow teachers and finish all exercises focusing on grammar and vocabulary) may not be a person who can communicate in English well in real life. They are not familiar with real-life situations and do not have a chance to communicate (like order, discuss, negotiate, complain, or make a decision) with partners. However, CLT activities provide them many opportunities to «talk in English» and turn their chance of communication into their experience for future communication. In fact, in CLT classes, learners are in the role of attendants and the center of the teaching and learning process. Therefore, attending classroom activities means learning a language and improving their language ability instead of finishing all given exercises. Consequently, learners have more motivation for language acquisition. Another undeniable strength of CLT is that it enhances and enriches learners' general knowledge and linguistic knowledge regardless of their language levels. Students with good English ability and learners with lower level can also learn in CLT classes because Richard (2006) confirms that CLT activities provide meaningful tasks and real like situations to develop language aspects, including maintaining conversation for learners with language limitations. Finally, teachers get benefits from CLT activities, too. To design CLT activities, teachers have to spend time on the preparation of material and suitable tasks. And, in classroom activities, teachers as the role of participant and 
facilitator directly or indirectly attend activities so that they have more practice to bettering their teaching career and also enlarge their knowledge by approaching authentic materials. In general, CLT provides tremendous benefit for both learners and teachers so that it should be introduced and widely applied into English classes in the university level for students who are just one step to enter life and the workforce.

\subsection{Disavantages of CLT in teaching and learning English as second language for university students}

CLT is orgininally introduced by native speakers and firstly used for native teachers so that it shows disadvantages when widely used for teaching ESL university students in other countries, especially Asian countries like Vietnam, Thailand, China, South Korea, Bangladesh, etc. Besides the benefits that CLT brings, several obstacles have been found in implementing this method. Firstly, common conflicts in Asian countries context cause the limited application of CLT. Written exams contribute to CLT's postponement into the real teaching and learning process (Dos Santos, 2020; Ahn \& Kang, 2017; Lee \& Lee, 2019). Asian education still relies on exams that are mainly written in written format so that teachers and students pay more attention to passing exams with flying colours than achieving better communicative ability. Therefore, at first, CLT seems not too suitable to learn English as a compulsory subject at school in Asia. However, if being considered in the main purpose of second language acquisition, CLT, with its principle, meets the needs of communicative output for students and motivates students to actively attend CLT activities. The conflicts between the effectiveness and real context cause the failure and postpone in widely implication of CLT. Secondly, although both teachers and students know the effectiveness of CLT, they are not very confident to apply this method. There are a lot of reasons such as lack of appropriate knowledge of CLT (Dos Santos, 2016, 2017; Abrejo et al., 2019), insufficient incentives to encourage teachers (Ozsevik, 2010), lack of authentic material (Tomlimson, 2001), students' hesitation and time constraints (Walia, 2012), language and cultural background of learners ( Dos Santos, 2020), the large size of classes (Weiner, 2012; Weiner \& Jerome, 2016). The implication of something new always encounter difficulties that come from different aspects. In particular, students in Asian countries, in particular, with a deep background of culture, postpone actively attending CLT activities more than Western learners. Attitude is one of the most important factors contributing to the effectiveness of implementing CLT. Although both teachers and students have a positive attitude towards CLT, the real implementation in different settings faces different obstacles. That can be seen as someone sees a beautiful dress but it needs modification to fit her body well. In western countries, students visit a factory, talk with the president, or attend real conversations to learn language and knowledge, whereas, in eastern countries, these real activities are fewer and difficult in the organisation. There are more researches on teacher's point of view than analysis CLT based on learners' viewpoint so that it lacks information to decide which teaching method is the most suitable for the students. Natividad and Batang (2018) point out that learners learn better in group work and spoken activities with actual experience. However, teachers without clear knowledge and experience in CLT cannot exploit the advantages of CLT method. In addition, there is some opposition against CLT. They claim that CLT aims at fluency more than accuracy, which is not very good in learning the language because Nunan (1989) explains that learners concentrate on meaning than the structures. Most university students are familiar with learning grammar, vocabulary or learn separated skills in their secondary education so that working with new teaching methods focussing on communication may make them confused and demotivated. Another factors cause the problem is material. Most of materials in unversity are not very updated with CLT spirit which causes difficulties for teachers in designing CLT activities. Authentic materials give learners benefits, whereas lack of appropriate material, the effectiveness of CLT will be influenced. Changing into CLT teaching material needs the authorities' approval and even needs the changes from the curriculum, which is not an easy thing. In Western countries, authentic materials can be found more easily than in Eastern and to be appropriate with Eastern culture, teachers have to smartly select material. Along with inappropriate material, teachers familiar with traditional teaching methods like GTM are not confident with CLT because they were not trained in any CLT courses. Some reject CLT because they do not want to change their normal teaching method, while a few claim that under-paid measures can not encourage teachers to apply new teaching methods like CLT in their practice. How much target language is another concerning element. It is not easy for teachers to use totally English for CLT activities in large and level differences because it can lead to demotivation for lower level students and if teachers use too much L1, higher-level students may get bored. Therefore, teachers have to be careful in preparation or pre-task and design appropriate activities that foster communicative competence for students. In general, the disadvantages may come from many factors and they negatively impact on implementing CLT, including large size classroom(Saengboon, 2002 ; Iwashita \& Ngoc, 2012; Weiner, 2012; Weiner \& Jerome, 2016), a belief of teacher and students, low motivation(Iwashita \& Ngoc, 2012; Pham, 2007 ; Dos Santos, 2020), examination format (Zhang, 2006), material (Jung \& Norton, 2002 ; Tomlimson, 2001), time limitation (Walia, 2012), culture background (Huang \& Yang, 2018) and lack of CLT knowledge (Dos Santos , 2016, 2017 ; Abrejo et al., 2019).

\subsection{Suggestions for implementing CLT effectively in teaching English as a second language in a university context}

Based on mentioned analysis about the advantages and disadvantages of CLT, the author suggests some implication of CLT in the university context. 
Firstly, textbooks nowadays update new teaching methods in their design and content. Teachers with knowledge of CLT can take advantage of the material to create communication activities in class like a problem-solving, interview, role-play, discussions, simulation, or information gap exchange. At first, students may face a lot of difficulties, but they will soon get familiar with reallife practice and improve their communicative competence. In addition, university students with a piece of rather wider knowledge than other levels can quickly adapt and contribute to CLT classes. Nunan (1989) states that 'A rule of thumb for authentic material is any material which has not been specifically produced for the purposes of language teaching.' Learning a language should go with authentic materials that provide real information, texts written by native authors, real-life reading and listening material so that learners understand and smoothly apply their linguistic and sociolinguistic skills in the classroom and then in their future working contexts. With the development of technology, especially the internet, teachers can easily find authentic material online and in real life. Learning cultures through authentic material is also very necessary because it enlarges student's knowledge and it is like good preparation for them to integrate into a different culture of the places they may visit. Therefore, students can also find comfort and familiarity when travelling to other countries or work in English-speaking environments because the real situations are not so different from what they approach at university classes.

Secondly, based on the English level of students, teachers can apply two main communications that Littlewood (1981) mentions, including functional communication activities to develop specific language skills or functions and social interaction activities to design conversation or discussion activities that require more knowledge of the language. As a result, teachers can provide new knowledge in implicit and explicit ways to create a natural learning environment for their classes and the teaching and learning will be more interesting than when the teacher takes the center role in class.

Thirdly, in term of the role of the teacher in CLT class, teachers should flexibly apply CLT in their classes and focus on particular aspects of communicative competence at each time. Students need to learn many skills instead of speaking only during the course (Dos Santos, 2020). Therefore, teachers should be flexible in the implementation of CLT method. In addition, CLT for different classes should be appropriate like lessons for English major class should be designed suitably for developing specific skills (listening, speaking, reading, or writing), integrated subjects (translation, interpretation), or English for a specific purpose ( business English, English for engineer, etc.) while lessons for non-major classes should focus more on communicative competence and mainly develop speaking ability because their outcome requires the fluency more than the accuracy like major ones.

Fourthly, Holliday (1994) states that a method is appropriate when sensitive and can adapt to any classroom. Therefore, based on the practical context, learner's need, the given syllabus, teachers with enough understanding of CLT consider different communicative activities suitable for their classes. The information gap is one of the most popular CLT activities because it involves students in real situations who need them to use all their linguistic information to exchange information they want. In other words, to have a successful conversation, students draw on their interlanguage repertoire (vocabulary and grammar) and communication strategies to get information and provide information for others. Jigsaw is another type of information gap. There are also other CLT activities such as puzzles, games, interview, survey, map reading, giving instruction or direction, discussion to give a final decision, spotting the differences, etc. Teachers can adapt these activities in teaching specific skills, not just speaking only because from the beginning. Many linguists agree that one of the tenets of CLT is that linguistic skill and communicative abilities should not be treated as isolated elements(Savignon, 1997). Brown (2014) claims that all skills that are related to communication are important.

Fifthly, teachers should not exclude focussing on the form because lack of language knowledge prevents students from reaching a higher level of development and negatively affects the accuracy of language aspects (Harley \& Swain, 1984; Spada \& Lightbown, 1989). Therefore, focus on form (implicit and explicit) and focus on meaning should be included to increase student's knowledge and use of that language. In the early development of CLT, some educators misunderstood that teaching in CLT method meant that grammar was exclusive (Thompson, 1996). However, Thompson also advises that CLT also allows teachers to teach grammar but in a different way in which learners look at the conversation or text first and recognise how the grammar works. Nowadays, many books design grammar activities through reading activities like Life of National Geographic or Introduction to English as a Second Language of Cambridge. It is useful for teachers because they also include speaking activities for each small part of a unit. Teachers can modify and design these activities into suitable tasks for their students' English levels.

Furthermore, input needs to be large. Teachers do not need to worry that without rich input, students cannot survive in CLT classes. Students with a rather mature brain and a quite large knowledge of the world will easily adapt into real life conversations at the university level. At first, they may be shy and do not voluntarily attend but with clear instructions and motivation from teachers, they will step by step get familiar with this method and show their improvement soon. In addition, authentic material can come from discourse sources that students hear the language from the teachers, classmates, multi-media, online videos, and any other sources. Doughty and Long (2003) mention that "realistic samples of discourse use surrounding native speaker and 
non-native speaker accomplishments of targeted tasks" (p. 61). Therefore, learners themselves can enrich their input and improve their language abilities spontaneously through CLT activities. One of the most common problems is that the authentic material may be not suitable for all students when they have different levels of English. To cope with this issue, (Brandl, 2019) suggests that teachers spend their time "locating suitable sources for materials and developing learning tasks that accompany the materials and scaffold the learning process" (p.23). Furthermore, the input should be comprehensible because, in a conversation, attendants face difficulties if they can not catch up with what their partners are saying. Brandl (2019) suggests using 'elaborating input' which is similar to the strategies that Doughty and Long (2003) mentions in case native speakers use to modify discourse to communicate comprehensibly with non-native speakers. These strategies include 'confirmation checks', 'comprehension checks', use of body language, use modified language through visual representations, repetitions, slower speech rate, etc.

Additionally, there is a need of maximizing the use of English in the classroom. It could bring a lot of benefits if students can use the most English in CLT classes. However, for a different level of English class, teachers adjust their CLT activities along with considering some aspects such as giving a clear guideline and instruction, setting a good sample for their students, from the beginning setting rules of using L1 in L2 classes, not allowing switch back and forth between languages in CLT activities (Brandl, 2019). Before CLT tasks, teachers can provide them with basic vocabulary or grammar useful in later activities and be clearer. Teachers can use L1 to check their understanding. That preparation is very necessary for students to get ready for conversation incomplete English. In addition, students nowadays make use of Google translation whenever they are lazy to read or cope with many new vocabularies. However, it is difficult to have a natural conversation if students have to translate during the time. Therefore, both teachers and students should carefully consider pre-task activities to have basic preparation for the main task. After main activities, teachers can give feedback and help students recognize their mistakes and increase their English accuracy. Negative feedback (or error correction) and positive feedback (confirms the correctness of student's performance) affect both teachers and learners so that giving feedback should be carefully considered by teachers. Lyster and Ranta (1997) mention recasts in which teachers correctly repeat their students error as one of the most widespread feedback, while Brandl (2019) adds 'direct corrective feedback' (in which teachers support by giving 'metalinguistic clues' or clarification requests' as a good way for students to repair their mistakes. The teacher avoids letting students down at their first performance because it can cause anxiety and students may build up a barrier against speaking English. Based on the real situation of classes, teachers choose suitable ways of giving feedback to help them recognise their mistakes and be willing to learn from their own mistakes and others.

Activities for CLT class need to be in variety. According to Courtney (2020), 'activities can be fun, meaningful, interactive, and routinely used to build and maintain a communicative culture in the classroom' (p.21). He introduces a lot of activities for Vietnamese contexts, including 'Draw a dream house' (-it 'encourages group work and builds rapport'), 'I'm not just a number' (focus on the order of question words and classmate's lives), 'Paragraph Pass' (refers to writing activity that encourages students to add sentences and it focuses on grammar structure and the meaning of ideas), and 'Market Place' (encourages students to share their own ideas). In his article, he gives very clear step-by-step instructions and introduces materials, rationale and tasks for each activity. In addition, CLT can be used for teaching and learning any skills, not just speaking, so that teachers can design CLT for reading like jigsaw, gap information, CLT for writing like adding ideas for a topic, CLT for reading listening like a combination between listening and speaking about that situation. Grammar can be taught implicitly through other skills.

Finally, authorities should pay more attention to updating teachers' teaching method by organizing offline and online training programs. Teachers are easily approaching material providing knowledge of CLT and how to design LCT activities effectively. In addition, CLT and other modern language teaching methods should be included in a university course for pedagogic students. In the near future, teachers with knowledge of CLT can turn normally traditional classes into CLT classes and contribute to improving the communicative competence for their students. As a result, the outcomes of university students can meet the need for social and international communication.

\section{Conclusion}

According to Larsen-Freeman (2000), "methods should not be understood as prescriptions for classroom behaviour and imposed on teachers as a strict set of procedures to follow. Rather, they should be used to help "expand a teacher's repertoire of techniques" and "provide an avenue for professional growth" (p. x). Therefore, the overview of CLT, including the related aspects, obstacles in implementation, the attitude of teachers and learners towards it, aims to supply a general view as well as encourage English teachers to adapt this method in their university context. Each method has its strengths and weaknesses, and the real application may lead to issues in a particular context. With its goals, main characteristics, and principles, CLT is a good way to foster university students' communicative competence. Effective implementation of CLT can bring a lot of benefits to teachers and students because this method exploits many different aspects of language knowledge and general knowledge to enhance sociolinguistic and strategic competence. During the history of CLT, this method causes several difficulties due to the conflicts of context, teacher and student's belief, lack of CLT training, and other minor factors. By synthesizing research on CLT in university,

Page | 55 
the author hopes that university teachers understand more about CLT and confidently register training course about designing CLT activities for their classes. These mentioned application of CLT method in the university environment are suggestions and they need further research to test the effectiveness. The article also suggests that future research on CLT focuses on students' point of view to analyze it from a different perspective to have more solutions for implementing CLT effectively in ESL classes in general and in the Asian context in particular.

Funding: This research received no external funding.

Acknowledgements: The author would like to thank Mr. Tran Tin Nghi for his helpful advice on various technical issues examined in this paper. The author, however, bears full responsibility for the paper.

Conflicts of Interest: The authors declare no conflict of interest.

\section{References}

[1] Abahussain, M. O. (2016). Implementing Communicative Language Teaching Method in Saudi Arabia: Challenges Faced by Formative Year Teachers in State Schools. (PhD). University of Stirling, Scotland.

[2] Abrejo, B., Sartaj, S., \& Memon, S. (2019). English Language Teaching through Communicative Approach: A Qualitative Study of Public Sector Colleges of Hyderabad, Sindh. Advances in Language and Literary Studies, 10(5), 43-49. https://doi.org/10.7575/aiac.alls.v.10n.5p.43

[3] Ahn, S.-Y., \& Kang, H.-S. (2017). South Korean university students' perceptions of different English varieties and their contribution to the learning of English as a foreign language. Journal of Multilingual and Multicultural Development, 38(8), 712-725. https://doi.org/10.1080/01434632.2016.1242595.

[4] Al-Nasser, A. S. (2015). Problems of English language acquisition in Saudi Arabia: An exploratory-cum-remedial study. Theory and Practice in Language Studies, 5(8), 1612- 1619.

[5] Alsalmi, A. A. (2014). Challenges confronting teachers of English language. (Master). Taif University, Taif.

[6] Bachman, L. (1990). Fundamental Considerations in Language Testing. Oxford: Oxford University Press.

[7] Batawi, G. H. (2007). Exploring the use of CLT in Saudi Arabia. (Master). American University of Sharjah, Sharjah.

[8] Borg, S. (2017). Teachers' beliefs and classroom practices. In The Routledge handbook of language awareness, (pp. 93-109): Routledge.

[9] Brandl, K. (2019). Communicative Language Teaching in Action: Putting Principles to Work. Pearson Education, Inc.

[10] Brandl, K., \& Bauer, G. (2002). Students' Perceptions of Novice Teaching Assistants' Use of the Target Language in Beginning Foreign Language Classes: Preliminary Investigation. In W. Davis, J. Smith, \& R. Smith (Eds), Ready To Teach: Graduate Teaching Assistants Prepare for Today and for Tomorrow (pp.128-138). Stillwater, OK: New Forums Press

[11] Brown, H. D. (2014). Principles of Language Learning and Teaching (6th ed.). White Plains, NY Pearson Education.

[12] Canale, M. \& Swain, M. (1980). Theoretical bases of communicative approaches to second language teaching and testing. Applied Linguistic, 1(1), 1-47.

[13] Chomsky, N. (1957). Syntactic structures. Mouton.

[14] Courtney, D. (2020). Activities to Activate and Maintain a Communicative Classroom. English Teaching Forum, 58(1), 10-21.

[15] Dos Santos, L. M. (2016). Foreign language teachers' professional development through peer observation programme. English Language Teaching, 9(10), 39-46. https://doi.org/10.5539/elt.v9n10p39.

[16] Dos Santos, L. M. (2017). How do teachers make sense of peer observation professional development in an Urban School. International Education Studies, 10(1), 255-265. https://doi.org/10.5539/ies.v10n1p255.

[17] Dos Santos., L. M. (2019). Science lessons for non-science university undergraduate students: An application of visual-only video teaching strategy. Journal of Engineering and Applied Sciences, 14(1), 308-311. https://doi.org/10.36478/jeasci.2019.308.311.

[18] Dos Santos, L. M. (2020). The Discussion of Communicative Language Teaching Approach in Language Classrooms, Journal of Education and e-Learning Research, 2020. Journal of Education and E-Learning, 7(2), 104-109.

[19] Doughty, C., \& Long, M. H. (2003). The handbook of second language acquisition. Blackwell Publishing.

[20] Harley, B., \& Swain, M. (1984). The interlanguage of immersion and its implications for second language teaching. In A. Davies, C. Criper, \& A. P. R. Howatt (Eds.), Interlanguage (pp. 291-311). Edinburgh: Edinburgh University Press.

[21] Huang, S.-H., \& Yang, L.-C. (2018). Teachers' Needs in the Advancement of Communicative Language Teaching (CLT) in Taiwan. TESOL International Journal, 13(1), 100-117.

[22] Holliday, A. (1994). Appropriate Methodology and Social Context. Cambridge: Cambridge University Press.

[23] Hymes, D. (1971). Pidginization and creolization of languages. London, UK: Cambridge University Press.

[24] Iwashita, N., \& Ngoc, K. M. (2012). A comparison of learners' and teachers' attitudes toward communicative language teaching at two universities in Vietnam. University of Sydney Papers in TESOL, 7, 25-49.

[25] Jung, S. K., \& Norton, B. (2002). Language planning in Korea: the new elementary English program. In Tollefson, J.W. (Ed.), Language policies in education: Critical issues (pp. 245-265). New Jersey: Lawrence Erlbaum Associates, Publishers.

[26] Kachru, B. (1992). World Englishes: approaches, issues and resources. Language Teaching, 25, 1-14.

[27] Kennedy, P. (2002). Learning cultures and learning styles: Myth-understandings about adult (Hong Kong) Chinese learners. International Journal of Lifelong Education, 21(5), 430-445. https://doi.org/10.1080/02601370210156745.

[28] Kiato, S. K., \& Kiato, K. (1996). Testing Communicative Competence. The TESOL Internet Journal, 2(5).

[29] Larsen-Freeman, D. (2000). Techniques and principles in language teaching (2nd ed.). New York: Oxford University Press.

[30] Lee, J. S., \& Lee, K. (2019). Perceptions of English as an international language by Korean English-major and non-English-major students. Journal of Multilingual and Multicultural Development, 40(1), 76-89.

[31] Li, D. (1998). It's always more difficult than you plan and imagine: Teachers' perceived difficulties in introducing the communicative approach in South Korea. TESOL Quarterly, 32(4), 677-703. 
[32] Littlewood, W. (1981). Communicative language teaching: An introduction. Cambridge: Cambridge University Press.

[33] Lyster, R., \& Ranta, L. (1997). Corrective feedback and learner uptake. Studies in Second Language Acquisition. https://doi.org/19. $10.1017 / \mathrm{S} 0272263197001034$.

[34] Natividad, M. R. A., \& Batang, B. L. (2018). Students' Perceptual Learning Styles and Attitudes toward Communicative Language Teaching. TESOL International Journal, 13(4), 104-120.

[35] Nunan, D. (1989). Designing tasks for the communicative classroom. Cambridge: Cambridge University Press.

[36] Nunan, D. (1991). Communicative tasks and the language curriculum. TESOL Quarterly, 25, 279-295.

[37] Ozsevik, Z. (2010). The use of communicative language teaching (CLT): Turkish EFL teachers' perceived difficulties in implementing CLT in Turkey. (Unpublished doctoral dissertation). University of Illiois at Urbana-Champaign, USA.

[38] Pennycook, A. (1994). The cultural politics of English as an international language. London: Longman.

[39] Pham, H. H. (2007). Communicative language teaching: unity within diversity. ELT Journal, 61(3), 193-201.

[40] Phillipson, R. (1992). Linguistic imperialism. Oxford, England: Oxford University Press.

[41] Riggenbach, H., \& Lazaraton, A. (1991). Promoting Oral Communication Skills. In M. Celce-Murcia (Ed.), Teaching English as a Second or Foreign Language (pp. 125-136). Los Angeles: University of California.

[42] Richards, J. C. (2006), Communicative language teaching today. New York: Cambridge University Press.

[43] Richards, J. C., \& Rodgers, T. (2001). Approaches and methods in language teaching. Cambridge: Cambridge University Press.

[44] Savignon, S. J. (1997). Communicative competence: Theory and classroom practice (2nd ed.). Sydney, NSW: McGraw-Hill.

[45] Saengboon, S. (2002). Beliefs of Thai EFL teachers about communicative language teaching. (Doctoral dissertation). Indiana University Bloomington, USA.

[46] Schulz, R.A. (1996). Focus on form in the foreign language classroom: Learners' and teachers' view on error correction and the role of grammar. Foreign Language Annals, 29(3), 333-364.

[47] Spada, N., \& Lightbown, P. M. (1989). Intensive ESL programs in Quebec primary schools. TESL Canada Journal, 7, 11-32.

[48] Souriyavongsa, T., Rany, S., Abidin, M. J. Z., \& Mei, L. L. (2013). Factors causes students low English language learning: A case study in the National University of Laos. International Journal of English Language Education, 1(1), 179-192.

[49] Thompson, G. (1996). Some misconceptions about communicative language teaching. ELT Journal, 50(1), 9-15.

[50] Tomlinson, B. (2001). Humanising the Coursebook. Humanising Language Teaching, 3(5).

[51] Walia, D. N. (2012). Traditional teaching methods vs. CLT: A study. Frontiers of language and teaching, 3(1), 125-131.

[52] Weiner, L. (2012). The future of our schools: Teachers unions and social justice. Chicago, IL: Haymarket Books.

[53] Weiner, L., \& Jerome, D. (2016). Urban teaching: The essentials (3rd ed.). New York, NY: Teachers College Press.

[54] West, A. J. (2016). Adaptation of Communicative Language Teaching Methodology to an English Textbook for English Language Learning of NIDA Students. PASAA, 52, 25-52

[55] Widdowson, H. G. (1990). Aspects of Language Teaching. Oxford: Oxford University Press.

[56] Zhang, J. L. (2006, November 11-13). The ecology of communicative language teaching: Reflecting on the Singapore experience [Paper presentation]. Annual CELEA International Conference: Innovating English Teaching: Communicative Language Teaching (CLT) and Other Approaches, China English Language Education Association (CELEA) and Guangdong University of Foreign Studies, Guangzhou, China. 